\title{
Controle genético da resistência da soja à raça 4 de Cercospora sojina ${ }^{(1)}$
}

\author{
Sebastião Martins Filho(2), Geraldo de Amaral Gravina ${ }^{(3)}$ e Carlos Sigueyuki Sediyama ${ }^{(3)}$
}

\begin{abstract}
Resumo - O objetivo deste trabalho foi estudar o controle genético da resistência à Cercospora sojina, em populações segregantes derivadas do cruzamento entre as cultivares de soja Paraná e Bossier. Foram avaliadas nos genitores e nas gerações $\mathrm{F}_{1}, \mathrm{~F}_{2}, \mathrm{RC}_{1}$ e $\mathrm{RC}_{2}$ seis características das plantas associadas com a doença: nota para infecção (NT); número de lesões por folíolo (NLF); diâmetro médio de lesão (DML); porcentagem de área foliar lesionada (PAFL); número de lesões por $\mathrm{cm}^{2}$ (NLC) e índice de doença (ID). A resistência da soja à cercosporiose comportou-se como um caráter quantitativo, e o efeito gênico aditivo o mais importante. As influências sobre NT foram as seguintes: efeito aditivo $(62,05 \%)$, efeito da dominância $(7,68 \%)$ e as interações epistáticas aditiva $\mathrm{x}$ aditiva, aditiva $\mathrm{x}$ dominante e dominante $\mathrm{x}$ dominante $(7,32 \%)$. $\mathrm{O}$ modelo aditivo-dominante foi suficiente para explicar as variações somente nos caracteres PAFL e NLC. A influência dos efeitos das interações epistáticas variaram de 2,22\% no caráter PAFL e em até 30,78\% no caráter DML. O modelo genético aditivo-dominante é satisfatório para explicar o comportamento da média das gerações em relação aos caracteres PAFL e NLC. Entretanto, quanto a NT, NLF, DML e ID, o modelo aditivo-dominante-epistático é o mais adequado.
\end{abstract}

Termos para indexação: Glycine max, epistasia, herança genética, mancha-olho-de-rã.

\section{Genetic control of soybean resistance to race 4 of Cercospora sojina}

\begin{abstract}
The objective of this work was to study the genetic control of resistance to frogeye leaf spot in segregating populations derived from the cross between Paraná and Bossier soybean cultivars. The progenitors and the $\mathrm{F}_{1}, \mathrm{~F}_{2}, \mathrm{RC}_{1}$ and $\mathrm{RC}_{2}$ generations were evaluated for six plant characters associated to the disease: infection grade (NT); number of lesions per foliole (NLF); average diameter of lesion (DML); percentage of lesioned foliar area (PAFL); number of lesions per square centimeter (NLC) and disease index (ID). Soybean resistance to frogeye leaf spot behaved as a quantitative character, and the additive genic effect was the most important character. The influences on NT were the following: additive effect (62.05\%), dominance effect (7.68\%) and additive $\mathrm{x}$ additive, additive $\mathrm{x}$ dominant and dominant $\mathrm{x}$ dominant epistatic interactions $(7.32 \%)$. The additive-dominant model was satisfactory to explain the variations only of PAFL and NLC characters. The influence of the effect of epistatic interactions varied from $2.22 \%$ for PAFL up to $30.78 \%$ for DML character. The additive-dominant genetic model is satisfactory to explain the behavior of the average of the generations of PAFL and NLC characters. However, for NT, NLF, DML and ID, the additive-dominant-epistatic model is more adequate.
\end{abstract}

Index terms: Glycine max, epistasis, genetic inheritance, frogeye leaf spot.

(1) Aceito para publicação em 13 de junho de 2002.

(2) Universidade Federal do Espírito Santo, Dep. de Engenharia Rural, Caixa Postal 16, CEP 29500-000 Alegre, ES. E-mail: smartins@npd.ufes.br

(3) Universidade Federal de Viçosa, Dep. de Fitotecnia, Avenida P. H. Rolfs, s/no, CEP 36571-000 Viçosa, MG. E-mail: gravina@alunos.ufv.br, csediyama@mail.ufv.br

\section{Introdução}

A cercosporiose (Cercospora sojina Hara), também conhecida por mancha-olho-de-rã, é uma das principais doenças foliares da soja [Glycine max (L.) Merrill]. Além das folhas, sementes, vagens e hastes também podem ser infectadas. A incidência da do- 
ença depende das condições de desenvolvimento da cultura (Akem \& Dashiell, 1994), sendo favorecida por ambientes quentes e úmidos (Sinclair \& Backman, 1989).

Essa doença foi responsável por grandes perdas de soja no Brasil, mas, atualmente, graças à utilização de cultivares resistentes, está sob controle. Sua ocorrência tem sido esporádica e está limitada ao sul do Maranhão e norte de Goiás (Yorinori \& Klingelfuss, 1999). Os mesmos autores relatam que o fungo apresenta grande variabilidade patogênica, com 23 raças já identificadas no Brasil, e que novas epidemias podem ocorrer.

Não há dados precisos sobre as perdas causadas pela mancha-olho-de-rã no Brasil. Entretanto, determinações de perdas, em parcelas experimentais e lavouras, em Londrina, PR, têm mostrado que os níveis de danos em cultivares suscetíveis atingem de $10 \%$ a $32 \%$ (Yorinori, 1992). A influência da doença na produtividade da soja é resultante da redução da área fotossintética, do desfolhamento prematuro e da produção de sementes danificadas e de má qualidade (Akem \& Dashiell, 1994). Atualmente, no Brasil, para se obter o registro de uma nova cultivar de soja no órgão oficial, é obrigatório que ela apresente resistência comprovada ao fungo.

O controle químico com fungicidas, além de caro, não é o meio mais eficiente de controle da mancha-olho-de-rã. $\mathrm{O}$ uso de cultivares resistentes é o meio mais econômico e eficiente de controle. O conhecimento da herança do caráter é fundamental para orientar os programas de melhoramento.

O objetivo deste trabalho foi estudar o controle genético da resistência à Cercospora sojina, em populações segregantes derivadas do cruzamento entre as cultivares de soja Paraná e Bossier.

\section{Material e Métodos}

O trabalho foi realizado em casa de vegetação com controle de temperatura $\left(28-34^{\circ} \mathrm{C}\right)$, no Departamento de Fitotecnia da Universidade Federal de Viçosa, em Viçosa, MG.

Foram avaliados, quanto à reação à $C$. sojina, raça 4 , os parentais Bossier e Paraná, as gerações $F_{1}$ e $F_{2}$ e o $R_{1}$ ( $F_{1} \times$ Bossier) e $\mathrm{RC}_{2}$ ( $\mathrm{F}_{1} \times$ Paraná). As populações avalia- das foram constituídas por 26 plantas, do genitor suscetível (Bossier), do genitor resistente (Paraná) e da geração $\mathrm{F}_{1} ; 219$ da $\mathrm{F}_{2} ; 56$ da $\mathrm{RC}_{1}$ e 60 da $\mathrm{RC}_{2}$.

Com o objetivo de uniformizar as plântulas, a semeadura foi feita em bandejas de plástico, contendo areia como leito de germinação, e, após a emergência, as plântulas foram repicadas para vasos de plástico com capacidade de $3 \mathrm{~L}$. O delineamento experimental foi o inteiramente casualizado e cada planta contida em um vaso representou uma repetição.

A população de $C$. sojina, raça 04 , foi obtida na Embrapa-Centro Nacional de Pesquisa de Soja, em Londrina, PR. Sua multiplicação foi realizada em placas de Petri contendo o meio de cultura suco de tomate sem tempero (Superbom)-ágar, cujo preparo foi semelhante ao preconizado para o meio V8-ágar (Veiga, 1973).

A obtenção, a multiplicação, a manutenção e o preparo do inóculo foram realizados de acordo com método adotado por Veiga (1973) e Cordeiro (1986).

A inoculação do patógeno ocorreu quando as plântulas apresentaram a terceira folha trifoliolada completamente desenvolvida. Cada planta foi pulverizada com $10 \mathrm{~mL}$ de uma suspensão de conídios contendo 40.000 conídios $/ \mathrm{mL}$. Após a inoculação, os vasos permaneceram, por três dias, sob umidade relativa de aproximadamente $100 \%$. Vinte dias após a inoculação, quando as plantas mostravam os sintomas característicos da doença, foram avaliados os seguintes caracteres: a) Nota para infecção (NT), utilizando a escala de notas visuais proposta por Ross (1968): 1,0: ausência de lesão; 2,0: presença de traços de lesões; 3,0: lesões de tamanho pequeno; 4,0: lesões de tamanho médio; e 5,0: lesões grandes. Na atribuição das notas, recorreu-se ao esquema apresentado por Cordeiro (1986); b) Número de lesões por folíolo (NLF): relativo à contagem no folíolo mais infectado da planta; c) Diâmetro médio da lesão (DML), em mm: com base na média das dez maiores lesões do folíolo mais infectado; d) Número de lesões por $\mathrm{cm}^{2}$ (NLC): número de lesões dividido pela área do folíolo; e) Porcentagem da área foliar lesionada (PAFL): área foliar lesionada (área média de lesão do folíolo mais infectado $\mathrm{x}$ número de lesões/área do folíolo) x 100; f) Índice de doença (ID): número de lesões por folíolo (NLF) x diâmetro médio de lesão (DML) ${ }^{2}$ (Veiga, 1973). As avaliações dos itens $b$ a f foram realizadas de acordo com método adotado por Veiga (1973) e Martins Filho et al. (2000).

Os estudos genéticos sobre a herança da resistência da soja à $C$. sojina, com base em médias e variâncias, foram 
realizados pelo método de Mather \& Jinks (1984), utilizando o programa computacional GENES (Cruz, 2001).

\section{Resultados e Discussão}

A resistência à $C$. sojina apresentou-se como um caráter quantitativo. As médias dos caracteres avaliados referentes às gerações $\mathrm{F}_{1}$ e $\mathrm{RC}_{2}$ posicionaramse próximas às do genitor resistente (Paraná), indicando a dominância da resistência (Tabela 1). As médias das gerações $\mathrm{F}_{2}$ e $\mathrm{RC}_{1}$ ficaram um pouco mais distante das médias do genitor resistente, como era de se esperar, pois em $\mathrm{F}_{2}$ há o efeito da segregação dos genes e em $\mathrm{RC}_{1}$ ocorre a expressão dos alelos recessivos. Houve alta variância relativa em alguns caracteres, como número de lesões por folíolo (NLF).
Uma possível explicação para essa alta variância pode ser o fato das lesões coalescerem, o que dificulta a avaliação do número de pontos lesionados em algumas folhas. Quanto às outras características analisadas, obtiveram-se menores variâncias, como foi o caso da nota para infecção (NT), uma variável considerada por Cordeiro (1986), Martins Filho (1999) e Barbieri et al. (2001) como muito confiável, apesar de ser subjetiva. A maior variância foi observada na população $\mathrm{F}_{2}$, em razão da maior segregação dos genes.

$\mathrm{Na}$ análise da predição do ganho por seleção, o sinal negativo é esperado porque se refere a características associadas com resistência à doenças, entretanto, algumas das variáveis analisadas têm sinal positivo (Tabela 2). Isto ocorreu com os caracteres DML, PAFL e NLC, porque estas são funções das

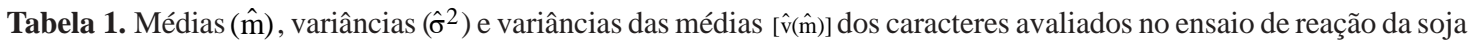
à Cercospora sojina Hara, em relação aos genitores e suas populações derivadas ${ }^{(1)}$.

\begin{tabular}{|c|c|c|c|c|c|c|c|c|c|}
\hline \multirow[t]{2}{*}{ População ${ }^{(2)}$} & \multicolumn{3}{|c|}{ NT } & \multicolumn{3}{|c|}{ NLF } & \multicolumn{3}{|c|}{ DML } \\
\hline & $\hat{\mathrm{m}}$ & $\hat{\sigma}^{2}$ & $\hat{\mathrm{v}}(\hat{\mathrm{m}})$ & $\hat{\mathrm{m}}$ & $\hat{\sigma}^{2}$ & $\hat{\mathrm{v}}(\hat{\mathrm{m}})$ & $\hat{\mathrm{m}}$ & $\hat{\sigma}^{2}$ & $\hat{\mathrm{v}}(\hat{\mathrm{m}})$ \\
\hline $\mathrm{P}_{1}$ & 4,60 & 0,1604 & 0,00617 & 139,69 & $1.872,78$ & 72,03 & 0,3481 & 0,0041 & 0,00016 \\
\hline $\mathrm{P}_{2}$ & 2,02 & 0,3236 & 0,01407 & 20,96 & 215,32 & 9,36 & 0,2196 & 0,0068 & 0,00029 \\
\hline $\mathrm{F}_{1}$ & 1,93 & 0,3886 & 0,01495 & 16,92 & 147,59 & 5,68 & 0,1154 & 0,0006 & 0,00002 \\
\hline $\mathrm{F}_{2}$ & 2,36 & 1,1585 & 0,00919 & 27,47 & 820,68 & 6,51 & 0,2313 & 0,0105 & 0,00008 \\
\hline $\mathrm{RC}_{1}$ & 2,57 & 1,0815 & 0,01803 & 19,73 & 279,62 & 4,66 & 0,3133 & 0,0235 & 0,00039 \\
\hline \multirow[t]{3}{*}{$\mathrm{RC}_{2}$} & 1,47 & 0,2895 & 0,00491 & 7,78 & 79,83 & 1,35 & 0,1322 & 0,0146 & 0,00025 \\
\hline & \multicolumn{3}{|c|}{ PAFL } & \multicolumn{3}{|c|}{ NLC } & \multicolumn{3}{|c|}{ ID } \\
\hline & $\hat{\mathrm{m}}$ & $\hat{\sigma}^{2}$ & $\hat{\mathrm{v}}(\hat{\mathrm{m}})$ & $\hat{\mathrm{m}}$ & $\hat{\sigma}^{2}$ & $\hat{\mathrm{v}}(\hat{\mathrm{m}})$ & $\hat{\mathrm{m}}$ & $\hat{\sigma}^{2}$ & $\hat{\mathrm{v}}(\hat{\mathrm{m}})$ \\
\hline $\mathrm{P}_{1}$ & 23,08 & 148,6081 & 5,7157 & 2,38 & 0,5604 & 0,0216 & 16,88 & 47,9776 & 1,8453 \\
\hline $\mathrm{P}_{2}$ & 2,65 & 9,0340 & 0,3928 & 0,47 & 0,1048 & 0,0046 & 1,53 & 3,0633 & 0,1332 \\
\hline $\mathrm{F}_{1}$ & 0,56 & 0,1478 & 0,0057 & 0,52 & 0,1200 & 0,0046 & 0,25 & 0,0486 & 0,0019 \\
\hline $\mathrm{F}_{2}$ & 4,69 & 63,3413 & 0,5027 & 0,55 & 0,3623 & 0,0029 & 2,98 & 24,8413 & 0,1972 \\
\hline $\mathrm{RC}_{1}$ & 12,06 & 228,8764 & 3,8146 & 1,00 & 0,7208 & 0,0120 & 3,25 & 20,2005 & 0,3367 \\
\hline $\mathrm{RC}_{2}$ & 1,66 & 4,9009 & 0,0831 & 0,37 & 0,1731 & 0,0029 & 0,46 & 0,4538 & 0,0077 \\
\hline
\end{tabular}

(1)NT: nota para infecção; NLF: número de lesões por folíolo; DML: diâmetro médio de lesão; PAFL: porcentagem de área foliar lesionada; NLC: número de lesões por $\mathrm{cm}^{2}$; ID: índice de doença. ${ }^{(2)} \mathrm{P}_{1}$ : Bossier; $\mathrm{P}_{2}$ : Paraná; $\mathrm{RC}_{1}: \mathrm{F}_{1} \times$ Bossier; $\mathrm{RC}_{2}$ : $\mathrm{F}_{1} \times$ Paraná.

Tabela 2. Predição de ganhos por seleção dos caracteres avaliados no ensaio da reação da soja à Cercospora sojina $\operatorname{Hara}^{(1)}$.

\begin{tabular}{|c|c|c|c|c|c|c|}
\hline Parâmetro & NT & NLF & DML & PAFL & NLC & ID \\
\hline Número de indivíduos selecionados & 25 & 25 & 25 & 25 & 25 & 25 \\
\hline Média original da $F_{2}$ & 2,36 & 27,47 & 0,23 & 4,69 & 0,55 & 2,98 \\
\hline Média dos indivíduos selecionados & 1,29 & 3,16 & 0,098 & 0,14 & 0,059 & 0,089 \\
\hline Diferencial de seleção & $-1,07$ & $-24,31$ & $-0,13$ & $-4,54$ & $-0,49$ & $-2,89$ \\
\hline Ganho por seleção & $-0,88$ & $-37,97$ & 0,00 & 0,00 & 0,00 & $-3,38$ \\
\hline Ganho por seleção (\%) & $-37,03$ & $-138,23$ & 0,00 & 0,00 & 0,00 & $-113,37$ \\
\hline Média predita para o $1^{\circ}$ ciclo após seleção & 1,49 & $-10,50$ & 0,45 & 12,37 & 0,779 & $-0,398$ \\
\hline
\end{tabular}

${ }^{(1)}$ NT: nota para infecção; NLF: número de lesões por folíolo; DML: diâmetro médio de lesão; PAFL: porcentagem de área foliar lesionada; NLC: número de lesões por $\mathrm{cm}^{2}$; ID: índice de doença. 
outras variáveis e tiveram suas estimativas de variância genética aditiva nulas, produzindo herdabilidades restritas nulas que, multiplicadas pelo diferencial de seleção, geraram predição de ganhos iguais a zero. Dessa forma, variáveis cujos resultados esperados no ganho com a seleção sejam negativos devem ser interpretadas. Os maiores ganhos, em porcentagem e com sinal negativo, foram preditos para a variável NLF, seguido de ID, AFL e NT, respectivamente. Nessa mesma ordem, para essas mesmas variáveis, foram obtidas maiores estimativas da herdabilidade no sentido restrito.

As interações não-alélicas foram significativas em relação aos caracteres NT, NLF, DML e ID, mas, para PAFLe NLC não diferiram significativamente de zero, a $5 \%$ de probabilidade, pelo teste t (Tabela 3 ).

Em genótipos selecionados, o efeito gênico aditivo é reduzido. Esse efeito é mais importante nos caracteres de herança menos complexa. Em caracteres quantitativos, de herança mais complexa, a contribuição dos efeitos gênicos decorrentes da dominância torna-se maior (Arias, 1986). Os caracteres governados pela ação gênica decorrente da dominância não podem ser fixados. Nesse caso a exploração da heterozigose é a única solução (Gamble, 1962). $\mathrm{O}$ efeito gênico associado à dominância foi o parâmetro que obteve a maior estimativa (porém com sinal negativo) e a maior variância nos caracteres ID, NLF, DMLe NT.

Apesar da decomposição não ser ortogonal, o coeficiente de determinação $\left(\mathrm{R}^{2}\right)$ dá idéia da importância de um particular efeito genético sobre a variabilidade disponível dos caracteres estudados (Tabela 4). Assim, não considerando o efeito da média, o efeito genético mais importante na determinação do

Tabela 3. Significância dos parâmetros genéticos do modelo completo, ajustado com base nas médias dos caracteres avaliados, no ensaio de reação de seis gerações de soja $\left(\mathrm{P}_{1}, \mathrm{P}_{2}, \mathrm{~F}_{1}, \mathrm{~F}_{2}, \mathrm{RC}_{1}, \mathrm{RC}_{2}\right)$ à Cercospora sojina $\mathrm{Hara}^{(1)}$.

\begin{tabular}{|c|c|c|c|c|c|c|c|c|c|}
\hline \multirow[t]{2}{*}{ Parâmetro $^{(2)}$} & \multicolumn{3}{|c|}{ NT } & \multicolumn{3}{|c|}{ NLF } & \multicolumn{3}{|c|}{ DML } \\
\hline & Estimativa & Variância & $\mathrm{t}$ & Estimativa & Variância & $\mathrm{t}$ & Estimativa & Variância & $\mathrm{t}$ \\
\hline$m$ & 4,68 & 0,2439 & $9,47 *$ & 135,17 & 148,62 & $11,08^{*}$ & 0,3181 & 0,0040 & $5,029 *$ \\
\hline $\mathrm{a}$ & 1,28 & 0,0051 & $18,10^{*}$ & 59,37 & 20,35 & $13,16^{*}$ & 0,0643 & 0,0001 & $6,05^{*}$ \\
\hline d & $-6,51$ & 1,4745 & $-5,36^{*}$ & $-312,57$ & 822,15 & $-10,90^{*}$ & $-0,1444$ & 0,0294 & $-0,84^{\mathrm{ns}}$ \\
\hline aa & $-1,37$ & 0,2388 & $-2,81^{*}$ & $-54,85$ & 128,27 & $-4,84 *$ & $-0,0343$ & 0,0039 & $-0,55^{\mathrm{ns}}$ \\
\hline $\mathrm{ad}$ & $-0,39$ & 0,1120 & $-1,16^{\mathrm{ns}}$ & $-94,82$ & 105,45 & $-9,23 *$ & 0,2337 & 0,0030 & $4,26 *$ \\
\hline \multirow[t]{3}{*}{ dd } & 3,76 & 0,5941 & $4,88 *$ & 194,32 & 304,53 & $11,14 *$ & $-0,0583$ & 0,0121 & $-0,53^{\mathrm{ns}}$ \\
\hline & \multicolumn{3}{|c|}{ PAFL } & \multicolumn{3}{|c|}{ NLC } & \multicolumn{3}{|c|}{ ID } \\
\hline & Estimativa & Variância & $\mathrm{t}$ & Estimativa & Variância & $\mathrm{t}$ & Estimativa & Variância & $\mathrm{t}$ \\
\hline $\mathrm{m}$ & 4,18 & 25,16 & $0,83^{\text {ns }}$ & 0,88 & 0,1123 & $2,62 *$ & 13,70 & 5,0265 & $6,11 *$ \\
\hline $\mathrm{a}$ & 10,21 & 1,53 & $8,27 *$ & 0,95 & 0,0065 & $11,81 *$ & 7,68 & 0,4946 & $10,91^{*}$ \\
\hline d & 5,65 & 186,24 & $0,41^{\mathrm{ns}}$ & $-0,95$ & 0,7855 & $-1,07^{\mathrm{ns}}$ & $-29,44$ & 29,4685 & $-5,42 *$ \\
\hline aa & 8,69 & 23,63 & $1,79^{\mathrm{ns}}$ & 0,55 & 0,1058 & $1,68^{\mathrm{ns}}$ & $-4,49$ & 4,5319 & $-2,11 *$ \\
\hline ad & 0,38 & 21,70 & $0,08^{\mathrm{ns}}$ & $-0,64$ & 0,0859 & $-2,19^{\mathrm{ns}}$ & $-9,77$ & 3,3559 & $-5,33^{*}$ \\
\hline dd & $-9,27$ & 76,54 & $-1,06^{\mathrm{ns}}$ & 0,59 & 0,3298 & $1,03^{\mathrm{ns}}$ & 15,99 & 10,6503 & $4,90 *$ \\
\hline
\end{tabular}

(1)NT: nota para infecção; NLF: número de lesões por folíolo; DML: diâmetro médio de lesão; PAFL: porcentagem de área foliar lesionada; NLC: número de lesões por $\mathrm{cm}^{2}$; ID: índice de doença. ${ }^{(2)} \mathrm{m}$ : média das linhagens homozigóticas derivadas de $\mathrm{F}_{2}$; a: medida do efeito gênico aditivo; d: medida dos desvios da dominância; aa: medida das interações aditivo x aditivo; ad: medida das interações aditivo x dominante; dd: medida das interações dominante $\mathrm{x}$

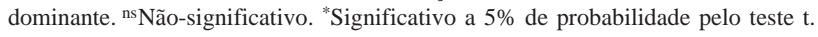

Tabela 4. Decomposição não-ortogonal da soma de quadrados de parâmetros (m, a, d, aa, ad, dd), pelo método de eliminação de Gauss dos caracteres avaliados no ensaio da reação à Cercospora sojina Hara em relação aos genitores e suas populações derivadas ${ }^{(1)}$.

\begin{tabular}{|c|c|c|c|c|c|c|c|c|c|c|c|c|}
\hline \multirow[t]{2}{*}{ Fonte de variação $^{(2)}$} & \multicolumn{2}{|c|}{ NT } & \multicolumn{2}{|c|}{ NLF } & \multicolumn{2}{|c|}{ DML } & \multicolumn{2}{|c|}{ PAFL } & \multicolumn{2}{|c|}{ NLC } & \multicolumn{2}{|c|}{ ID } \\
\hline & SQ & $\mathrm{R}^{2}(\%)$ & SQ & $\mathrm{R}^{2}(\%)$ & SQ & $\mathrm{R}^{2}(\%)$ & SQ & $\mathrm{R}^{2}(\%)$ & SQ & $\mathrm{R}^{2}(\%)$ & SQ & $\mathrm{R}^{2}(\%)$ \\
\hline $\mathrm{m} / \mathrm{a}, \mathrm{d}, \mathrm{aa}, \mathrm{ad}, \mathrm{dd}$ & 0,89 & 18,38 & 745,77 & 7,30 & 0,0041 & 22,81 & 0,71 & 0,33 & 0,03 & 1,64 & 7,66 & 5,22 \\
\hline $\mathrm{a} / \mathrm{m}, \mathrm{d}, \mathrm{aa}, \mathrm{ad}, \mathrm{dd}$ & 3,31 & 68,13 & $7.049,09$ & 69,05 & 0,0083 & 45,59 & 208,68 & 97,34 & 1,82 & 94,90 & 117,83 & 80,30 \\
\hline $\mathrm{d} / \mathrm{m}, \mathrm{a}, \mathrm{aa}, \mathrm{ad}, \mathrm{dd}$ & 0,30 & 6,17 & 690,44 & 6,76 & 0,0002 & 0,81 & 0,23 & 0,11 & 0,01 & 0,33 & 6,12 & 4,17 \\
\hline $\mathrm{aa} / \mathrm{m}, \mathrm{a}, \mathrm{d}, \mathrm{ad}, \mathrm{dd}$ & 0,08 & 1,61 & 125,34 & 1,23 & 0,0001 & 0,27 & 3,15 & 1,47 & 0,01 & 0,65 & 0,84 & 0,57 \\
\hline $\mathrm{ad} / \mathrm{m}, \mathrm{a}, \mathrm{d}, \mathrm{aa}, \mathrm{dd}$ & 0,02 & 0,31 & 899,24 & 8,81 & 0,0055 & 30,17 & 0,01 & 0,01 & 0,04 & 2,14 & 9,55 & 6,51 \\
\hline $\mathrm{dd} / \mathrm{m}, \mathrm{a}, \mathrm{d}, \mathrm{aa}, \mathrm{ad}$ & 0,26 & 5,40 & 699,24 & 6,85 & 0,0001 & 0,35 & 1,59 & 0,74 & 0,01 & 0,34 & 4,73 & 3,23 \\
\hline Total & 4,86 & 100,00 & $10.209,12$ & 100,00 & 0,0181 & 100,00 & 214,37 & 100,00 & 1,92 & 100,00 & 146,74 & 100,00 \\
\hline
\end{tabular}

${ }^{(1) N T: ~ n o t a ~ p a r a ~ i n f e c c ̧ a ̃ o ; ~ N L F: ~ n u ́ m e r o ~ d e ~ l e s o ̃ e s ~ p o r ~ f o l i ́ o l o ; ~ D M L: ~ d i a ̂ m e t r o ~ m e ́ d i o ~ d e ~ l e s a ̃ o ; ~ P A F L: ~ p o r c e n t a g e m ~ d e ~ a ́ r e a ~ f o l i a r ~ l e s i o n a d a ; ~ N L C: ~ n u ́ m e r o ~}$ de lesões por $\mathrm{cm}^{2}$; ID: índice de doença. ${ }^{(2)} \mathrm{m}$ : média das linhagens homozigóticas derivadas de $\mathrm{F}_{2}$; a: medida do efeito gênico aditivo; d: medida dos desvios da dominância; aa: medida das interações aditivo $\mathrm{x}$ aditivo; ad: medida das interações aditivo $\mathrm{x}$ dominante; dd: medida das interações dominante $\mathrm{x}$ dominante. 
caráter NT foi o efeito gênico aditivo $(68,13 \%)$, enquanto o efeito decorrente da dominância foi o de menor importância $(6,17 \%)$. Esse fato evidencia a possibilidade de obtenção de materiais homozigóticos superiores, por meio de seleção, a partir da geração $F_{2}$ e que os ganhos nos ciclos de seleção serão satisfatórios, uma vez que o componente de natureza aditiva é de elevada magnitude. Com relação ao caráter NT, evidencia-se que as interações epistáticas aditiva $\mathrm{x}$ aditiva, aditiva $\mathrm{x}$ dominante e dominante $\mathrm{x}$ dominante influíram, em $7,32 \%$, na determinação das médias das gerações estudadas (Tabela 4). Logo, os resultados sugerem que o modelo aditivo-dominante pode explicar a maior parte das variações nesse caráter, em razão da baixa contribuição dos efeitos das interações epistáticas. Entretanto, o uso desse modelo reduzido está sujeito a um viés, porque as epistasias aa e dd foram significativas e não devem ser desconsideradas. Esse mesmo raciocínio pode ser estendido para os demais caracteres.

Conforme revisão de Arias (1986), os efeitos de dominância e as interações gênicas são de menor importância nas espécies autógamas. Porém, as interações gênicas entre genes não alélicos, ou epistáticas, ou dialélicas, não podem ser desconsideradas nos mecanismos genéticos básicos. Modelos genéticos, que negligenciam as epistasias, podem estar de alguma maneira viesados, conforme Quinby (1963), citado por Scapim (1997).

Mesmo que o uso do modelo genético completo para descrever as médias da geração seja de grande importância para o conhecimento mais abrangente das causas e magnitudes dos componentes genéticos que controlam o caráter, pode-se também avaliar o modelo reduzido aditivo-dominante que, além de mais simples, tem sido rotineiramente utilizado no melhoramento, para prover as informações indispensáveis na avaliação da eficiência de métodos empregados e do êxito dos mesmos.

Em todos os caracteres, considerando o modelo reduzido aditivo-dominante, a média foi o parâmetro em que se obteve a maior estimativa; o efeito gênico decorrente da dominância, a maior variância, e todos os parâmetros estimados diferiram significativamente de zero, a $5 \%$ de probabilidade, pelo teste $t$ (Tabela 5).

$\mathrm{O}$ modelo aditivo-dominante possibilita a obtenção de médias preditas que se correlacionam com as médias observadas em magnitudes elevadas em todos os caracteres analisados, variando de $87,84 \%$ na característica de maior variabilidade (NLF), a 98,29\%, na PAFL (Tabela 6). No caso de NT, considerado como o caráter mais importante entre os avaliados, observou-se correlação de 95,09\%. Esses valores equivalem às determinações de $77,71 \%, 96,60 \% \mathrm{e}$ 90,41\% em relação aos caracteres NLF, PAFLe NT, respectivamente.

O uso do modelo genético aditivo-dominante é satisfatório para explicar o comportamento da média das gerações, nos caracteres em estudo. A variabilidade aditiva, presente em $\mathrm{F}_{2}$, é relativamente superior à atribuída aos desvios da dominância quanto aos caracteres NT, NLF e NLC e o oposto ocorre em relação aos caracteres DML, PAFLe ID (Tabela 7). En-

Tabela 5. Teste de significância da nulidade de modelos menos parametrizados dos parâmetros genéticos, obtidos das médias de seis gerações $\left(\mathrm{P}_{1}, \mathrm{P}_{2}, \mathrm{~F}_{1}, \mathrm{~F}_{2}, \mathrm{RC}_{1}, \mathrm{RC}_{2}\right)$ de plantas de soja, dos caracteres avaliados no ensaio da reação à Cercospora sojina Hara em relação aos genitores e suas populações derivadas ${ }^{(1)}$.

\begin{tabular}{|c|c|c|c|c|c|c|c|c|c|}
\hline \multirow[t]{2}{*}{ Parâmetro ${ }^{(2)}$} & \multicolumn{3}{|c|}{ NT } & \multicolumn{3}{|c|}{ NLF } & \multicolumn{3}{|c|}{ DML } \\
\hline & Estimativa & Variância & $\mathrm{t}$ & Estimativa & Variância & $\mathrm{t}$ & Estimativa & Variância & $\mathrm{t}$ \\
\hline $\mathrm{m}$ & 3,16 & 0,0040 & $50,12 *$ & 36,33 & 6,10 & $14,70 *$ & 0,30 & 0,000075 & $34,24 *$ \\
\hline $\mathrm{a}$ & 1,37 & 0,0037 & $22,43 *$ & 22,08 & 4,34 & $10,60 *$ & 0,08 & 0,000092 & $8,04^{*}$ \\
\hline \multirow[t]{3}{*}{ d } & $-1,65$ & 0,0171 & $-12,58^{*}$ & $-29,88$ & 15,86 & $-7,50 *$ & $-0,18$ & 0,000108 & $-17,03^{*}$ \\
\hline & \multicolumn{3}{|c|}{ PAFL } & \multicolumn{3}{|c|}{ NLC } & \multicolumn{3}{|c|}{ ID } \\
\hline & Estimativa & Variância & $\mathrm{t}$ & Estimativa & Variância & $\mathrm{t}$ & Estimativa & Variância & $\mathrm{t}$ \\
\hline $\mathrm{m}$ & 11,51 & 0,7067 & $13,69^{*}$ & 1,15 & 0,0040 & $18,16^{*}$ & 5,78 & 0,1612 & $14,40^{*}$ \\
\hline $\mathrm{a}$ & 8,92 & 0,7650 & $10,20 *$ & 0,76 & 0,0041 & $11,84^{*}$ & 4,94 & 0,1650 & $12,15^{*}$ \\
\hline d & $-10,95$ & 0,7192 & $-12,91 *$ & $-0,81$ & 0,0102 & $-8,03 *$ & $-5,55$ & 0,1658 & $-13,62^{*}$ \\
\hline
\end{tabular}

(1)NT: nota para infecção; NLF: número de lesões por folíolo; DML: diâmetro médio de lesão; PAFL: porcentagem de área foliar lesionada; NLC: número de lesões por $\mathrm{cm}^{2}$; ID: índice de doença. ${ }^{(2)} \mathrm{m}$ : média das linhagens homozigóticas derivadas de $\mathrm{F}_{2}$; a: medida do efeito gênico aditivo; d: medida dos desvios da dominância. *Significativo a $5 \%$ de probabilidade pelo teste $t$. 
Tabela 6. Médias observadas e estimadas de plantas de seis gerações $\left(\mathrm{P}_{1}, \mathrm{P}_{2}, \mathrm{~F}_{1}, \mathrm{~F}_{2}, \mathrm{RC}_{1}, \mathrm{RC}_{2}\right)$ de soja, dos caracteres avaliados no ensaio da reação à Cercospora sojina Hara em relação aos genitores e suas populações derivadas ${ }^{(\mathbf{1})}$.

\begin{tabular}{|c|c|c|c|c|c|c|c|c|c|c|c|c|}
\hline \multirow[t]{2}{*}{ População $^{(2)}$} & \multicolumn{2}{|c|}{ NT } & \multicolumn{2}{|c|}{ NLF } & \multicolumn{2}{|c|}{ DML } & \multicolumn{2}{|c|}{ PAFL } & \multicolumn{2}{|c|}{ NLC } & \multicolumn{2}{|c|}{ ID } \\
\hline & $\begin{array}{c}\text { Média } \\
\text { observada }\end{array}$ & $\begin{array}{c}\text { Média } \\
\text { estimada }\end{array}$ & $\begin{array}{c}\text { Média } \\
\text { observada }\end{array}$ & $\begin{array}{c}\text { Média } \\
\text { estimada }\end{array}$ & $\begin{array}{c}\text { Média } \\
\text { observada }\end{array}$ & $\begin{array}{c}\text { Média } \\
\text { estimada }\end{array}$ & $\begin{array}{c}\text { Média } \\
\text { observada }\end{array}$ & $\begin{array}{c}\text { Média } \\
\text { estimada }\end{array}$ & $\begin{array}{c}\text { Média } \\
\text { observada }\end{array}$ & $\begin{array}{c}\text { Média } \\
\text { estimada }\end{array}$ & $\begin{array}{c}\text { Média } \\
\text { observada }\end{array}$ & $\begin{array}{c}\text { Média } \\
\text { estimada }\end{array}$ \\
\hline$\overline{\mathrm{P}_{1}}$ & 4,60 & 4,52 & 139,69 & 58,40 & 0,3481 & 0,3730 & 23,08 & 20,43 & 2,38 & 1,91 & 16,88 & 10,71 \\
\hline $\mathrm{P}_{2}$ & 2,02 & 1,79 & 20,96 & 14,25 & 0,2196 & 0,2190 & 2,65 & 2,59 & 0,47 & 0,39 & 1,53 & 0,84 \\
\hline $\mathrm{F}_{1}$ & 1,93 & 1,51 & 16,92 & 6,45 & 0,1154 & 0,1187 & 0,56 & 0,56 & 0,52 & 0,34 & 0,25 & 0,23 \\
\hline $\mathrm{F}_{2}$ & 2,36 & 2,33 & 27,47 & 21,39 & 0,2313 & 0,2073 & 4,69 & 6,03 & 0,55 & 0,75 & 2,98 & 3,01 \\
\hline $\mathrm{RC}_{1}$ & 2,57 & 3,02 & 19,73 & 32,43 & 0,3133 & 0,2458 & 12,06 & 10,49 & 1,00 & 1,12 & 3,25 & 5,47 \\
\hline $\mathrm{RC}_{2}$ & 1,47 & 1,65 & 7,78 & 10,35 & 0,1322 & 0,1689 & 1,66 & 1,57 & 0,37 & 0,37 & 0,46 & 0,54 \\
\hline $\mathrm{r}\left(\mathrm{y}_{\mathrm{obs}}, \mathrm{y}_{\mathrm{est}}\right)^{(3)}$ & & 0,96 & & 0,90 & & 0,92 & & 0,99 & & 0,96 & & 0,94 \\
\hline$\overline{\mathrm{R}^{2}}$ & & 0,93 & & 0,81 & & 0,84 & & 0,99 & & 0,93 & & 0,89 \\
\hline
\end{tabular}

${ }^{(1)}$ NT: nota para infecção; NLF: número de lesões por folíolo; DML: diâmetro médio de lesão; PAFL: porcentagem de área foliar lesionada; NLC: número de lesões por $\mathrm{cm}^{2}$; ID: índice de doença. ${ }^{(2)} \mathrm{P}_{1}$ : Bossier; $\mathrm{P}_{2}$ : Paraná; $\mathrm{RC}_{1}: \mathrm{F}_{1} \mathrm{x}$ Bossier; $\mathrm{RC}_{2}$ : $\mathrm{F}_{1} \mathrm{x}$ Paraná. ${ }^{(3)}$ Correlação entre valores observados e estimados.

Tabela 7. Decomposição não-ortogonal da soma de quadrados de parâmetros (m, a, d) pelo método de eliminação de Gauss dos caracteres avaliados no ensaio da reação à Cercospora sojina Hara $^{(1)}$.

\begin{tabular}{|c|c|c|c|c|c|c|c|c|c|c|c|c|}
\hline \multirow[t]{2}{*}{ Fonte de variação $^{(2)}$} & \multicolumn{2}{|c|}{ NT } & \multicolumn{2}{|c|}{ NLF } & \multicolumn{2}{|c|}{ DML } & \multicolumn{2}{|c|}{ PAFL } & \multicolumn{2}{|c|}{ NLC } & \multicolumn{2}{|c|}{ ID } \\
\hline & SQ & $\mathrm{R}^{2}(\%)$ & SQ & $\mathrm{R}^{2}(\%)$ & SQ & $\mathrm{R}^{2}(\%)$ & SQ & $\mathrm{R}^{2}(\%)$ & SQ & $\mathrm{R}^{2}(\%)$ & SQ & $\mathrm{R}^{2}(\%)$ \\
\hline $\mathrm{m} / \mathrm{a}, \mathrm{d}$ & $2.512,12$ & 79,15 & 216,22 & 56,19 & $1.172,12$ & 76,77 & 187,44 & 40,90 & 329,74 & 61,71 & 207,24 & 38,36 \\
\hline $\mathrm{a} / \mathrm{m}, \mathrm{d}$ & 503,24 & 15,86 & 112,31 & 29,19 & 64,63 & 4,23 & 104,03 & 22,70 & 140,08 & 26,22 & 147,60 & 27,32 \\
\hline $\mathrm{d} / \mathrm{m}, \mathrm{a}$ & 158,36 & 4,99 & 56,28 & 14,62 & 290,07 & 19,00 & 166,77 & 36,39 & 64,50 & 12,07 & 185,45 & 34,32 \\
\hline Total & $3.173,72$ & 100,00 & 384,81 & 100,00 & $1.526,83$ & 100,00 & 458,24 & 100,00 & 534,32 & 100,00 & 540,28 & 100,00 \\
\hline
\end{tabular}

(1)NT: nota para infecção; NLF: número de lesões por folíolo; DML: diâmetro médio de lesão; PAFL: porcentagem de área foliar lesionada; NLC: número de lesões por $\mathrm{cm}^{2}$; ID: índice de doença. ${ }^{(2)} \mathrm{m}$ : média das linhagens homozigóticas derivadas de $\mathrm{F}_{2}$; a: medida do efeito gênico aditivo; d: medida dos desvios da dominância.

tretanto, como existe um consenso entre os pesquisadores em se utilizar a nota para infecção (NT) e considerando esta a característica de trabalho escolhida, o melhorista terá possibilidade de obter materiais homozigóticos superiores, a partir da geração $\mathrm{F}_{2}$.

\section{Conclusões}

1. A resistência a Cercospora sojina em soja comporta-se como um caráter quantitativo.

2. Os efeitos genéticos mais importantes na determinação dos caracteres relacionados com a resistência são os efeitos gênico aditivo e de dominância, que se alteram de acordo com o caráter avaliado.

3. Os caracteres nota para infecção, número de lesões por folíolo e número de lesões por $\mathrm{cm}^{2}$ apresentam maiores valores estimados de efeitos gênicos aditivos do que efeitos gênicos de dominância; os caracteres diâmetro médio de lesão, porcentagem de área foliar lesionada e índice de doença comportam-se de forma oposta.

4. A nota para infecção pode ser utilizada em programas de melhoramento para resistência a Cercospora sojina.
5. Os caracteres nota para infecção, número de lesões por folíolo, diâmetro médio de lesão e índice de doença apresentam interações epistáticas significativas, e devem ser avaliados pelo modelo aditivo-dominante-epistático; os caracteres porcentagem de área foliar lesionada e número de lesões por $\mathrm{cm}^{2}$ podem ser analisados utilizando o modelo aditivo-dominante.

\section{Referências}

AKEM, C. N.; DASHIELL, K. E. Effect of planting date on severity of frogeye leaf spot and grain yield of soybeans. Crop Protection, Oxford, v. 13, n. 8, p. 607-610, 1994.

ARIAS, E. R. A. Teste de escala conjunta na estimação de parâmetros genéticos em soja (Glycine max (L.) Merrill). 1986. 86 f. Dissertação (Mestrado em Genética e Melhoramento) - Universidade Federal de Viçosa, Viçosa, MG, 1986.

BARBIERI, R. L.; CARVALHO, F. I. F.; BARBOSA NETO, J. F.; CAETANO, V. R.; MARCHIORO, V. S.; AZEVEDO, R.; LONRECETTI, C. Análise dialélica para 
tolerância ao vírus-do-nanismo-amarelo-da-cevada em cultivares brasileiras de trigo. Pesquisa Agropecuária Brasileira, Brasília, v. 36, n. 1, p. 131-135, jan. 2001.

CORDEIRO, A. C. C. Herança da resistência da soja (Glycine max (L.) Merrill), a Cercospora sojina Hara, isolado de São Gotardo, Minas Gerais. 1986. 61 f. Dissertação (Mestrado em Genética e Melhoramento) - Universidade Federal de Viçosa, Viçosa, MG, 1986.

CRUZ, C. D. Programa Genes: aplicativo computacional em genética e estatística: versão Windows. Viçosa, MG: Editora UFV, 2001. 648 p.

GAMBLE, E. E. Gene effects in corn (Zea mays L.) - I: separation and relative importance of gene effects for yield. Canadian Journal of Plant Science, Ottawa, v. 42, p. 339-348, 1962.

MARTINS FILHO, S. Estudo da mancha olho-de-rã da soja (Glycine max (L.) Merrill): análise genética, herança da resistência e identificação de marcadores moleculares. 1999. 82 f. Tese (Doutorado em Genética e Melhoramento) - Universidade Federal de Viçosa, Viçosa, MG, 1999.

MARTINS FILHO, S.; SEDIYAMA, C. S.; MOREIRA, M. A.; BARROS, E. G. Herança da resistência da soja (Glycine max (L.) Merrill) a Cercospora sojina Hara. AgroCiencia, Chillán, v. 16, n. 2, p. 183-188, 2000.
MATHER, F. R. S.; JINKS, F. R. S. Introdução à genética biométrica. Ribeirão Preto: Sociedade Brasileira de Genética, 1984. 390 p.

ROSS, J. P. Additional physiological races of Cercospora sojina on soybeans in North Carolina. Phytopathology, St. Paul, v. 58, n. 5, p. 708-709, 1968.

SCAPIM, C. A. Efeitos gênicos, heterose e depressão endogâmica em caracteres de sorgo granífero e forrageiro (Sorghum bicolor (L.) Moench). 1997. $89 \mathrm{f}$. Tese (Doutorado em Genética e Melhoramento) - Universidade Federal de Viçosa, Viçosa, MG, 1997.

SINCLAIR, J. B.; BACKMAN, P. A. Frogeye leaf spot. In: SINCLAIR, J. B.; BACKMAN, P. A. (Ed.). Compendium of soybean diseases. 3. ed. St. Paul: American Phytopathological Society, 1989. p. 19-21.

VEIGA, P. Cercospora sojina Hara: obtenção de inóculo, inoculação e avaliação da resistência em soja (Glycine max (L.) Merrill). 1973. 32 f. Dissertação (Mestrado em Agronomia) - Escola Superior de Agricultura Luiz de Queiroz, Piracicaba, 1973

YORINORI, J. T. Management of foliar fungal diseases in soybean in Brazil. In: COPPING, L. G.; GREEN, M. B.; REES, R. T. (Ed.). Pest management in soybean. London: Elsevier Applied Science, 1992. p. 185-193.

YORINORI, J. T.; KLINGELFUSS, L. H. Novas raças de Cercospora sojina em soja. Fitopatologia Brasileira, Brasília, v. 24, n. 4, p. 509-512, 1999. 